\title{
Seroprevalence of Hepatitis A and E Virus Infections Among Healthy Population in Shiraz, Southern Iran
}

\author{
Sadaf Asaei ${ }^{1}$; Mazyar Ziyaeyan ${ }^{1,3}$; Mahsa Moeini ${ }^{1}$; Marzieh Jamalidoust ${ }^{1,2}$; Mohammad \\ Amin Behzadi ${ }^{1}$ \\ ${ }_{1}^{1}$ Department of Virology, Professor Alborzi Clinical Microbiology Research Center, Nemazi Hospital, Shiraz University of Medical Sciences, Shiraz, IR Iran \\ ${ }^{2}$ Department of Medical Virology, Faculty of Medical Sciences, Tarbiat Modares University, Tehran, IR Iran \\ *Corresponding author: Mazyar Ziyaeyan, Department of Virology, Professor Alborzi Clinical Microbiology Research Center, Nemazi Hospital, Shiraz University of Medical Sciences, \\ P. O. Box: 71937-11351, Shiraz, IR Iran. Tel: +98-7116474304, Fax:+98-7116474303, E-mail: ziyaeyanm@sums.ac.ir
}

Received: April 6, 2014; Revised: June 14, 2014; Accepted: June 24, 2014

\begin{abstract}
Background: Enterically-transmitted acute viral hepatitis is caused predominantly by hepatitis A virus (HAV) and hepatitis Evirus (HEV). The prevalence of HEV and HAV infections varies in different geographical regions.

Objectives: This study was conducted to determine the prevalence of HEV and HAV infections among Iranian healthy individuals in southern Iran.

Patients and Methods: Totally, 1030 samples were collected from healthy subjects in schools, those referred to tertiary outpatient clinics and health centers in Shiraz between November 2011 and May 2012. Their ages ranged between six months and 95 years. The presence of total anti-HAV and anti-HEV immunoglobulin M (IgM) in plasma was assessed by ELISA.

Results: The results showed that $66.2 \%$ and $0.6 \%$ of the general population in this area were positive for total anti-HAV and IgM antibodies by ELISA, respectively. As seen, $13.4 \%$ and $0.9 \%$ were positive for total anti-HEV and IgM antibodies, respectively. The difference in total antiHAV and anti-HEV antibodies was significant among the age groups $(\mathrm{P}<0.001)$.

Conclusions: This study showed that the prevalence rates of HAV and HEV antibodies were positively correlated with age. The results demonstrated that the infection with these two viruses in the region was high and some high-risk individuals including females at childbearing age were more susceptible. HAV vaccination could be recommended for antibody-negative adults.
\end{abstract}

Keywords: Seroepidemiological Study; Iran; Hepatitis E Virus; Hepatitis A Virus

\section{Background}

Hepatitis A virus (HAV) is a single-strand RNA virus belonging to Picornaviridae with $7500 \mathrm{~b}$ length. Its genome consists of a single open reading frame (ORF) which encodes a polyprotein, divided into three regions (P1-P3). P1 encodes four structural proteins and P2-P3 encode seven nonstructural proteins (1). The incubation period of this acute infection is 2 - 6 weeks (2).

$\mathrm{HAV}$ infection is a considerable hygienic problem in developing countries with low socioeconomic conditions, especially among some specific populations such as injection drug abusers and patients with clotting factors disorders. This infection is transmitted person to person through fecal-oral route $(3,4)$. Seafood can be a common HAV infection source if not cooked well. The pattern and prevalence of HAV infection vary greatly in different geographical regions and different populations. Seroepidemiological studies have shown that the prevalence of HAV is closely associated with economic and cultural status (5). Its incidence rate in the world ranges from as low as $13 \%$ in Scandinavian countries to nearly $100 \%$ in developing countries such as those in Asia, Africa and South America (3). In European countries, HAV incidence in the north is lower than that in the south (2). Therefore, performing serological test seems to be necessary in our region.

Hepatitis E virus (HEV), a small nonenveloped RNA virus and a member of Caliciviridae, is similar to HAV, whose main route of transmission is fecal-oral and through contaminated water in developing nations. Unlike HAV, HEV may be a zoonotic disease, especially in industrialized nations (6). It has a worldwide distribution and is endemic in Asia, Africa, Middle East and Central America (7), while its outbreak mostly occurs in rainy seasons and in overcrowding (8). HEV infection can be more severe in pregnant women with average of fatality reported to be $25 \%$ among them (7). Iran is notably located in the HEV endemic areas (9).

\section{Objectives}

Considering the facts that HAV and HEV are food and

Copyright (C) 2015, Ahvaz Jundishapur University of Medical Sciences. This is an open-access article distributed under the terms of the Creative Commons Attribution-NonCommercial 4.0 International License (http://creativecommons.org/licenses/by-nc/4.0/) which permits copy and redistribute the material just in noncommercial usages, provided the original work is properly cited. 
waterborne pathogens with the same routes of transmission and mechanisms of spread, causing similarly severe epidemics, the present seroepidemiological study of HAV and HEV infections aimed to determine the prevalence of such infections among different age groups in Shiraz, southern Iran. By doing so, some ways of controlling the infections and preventing new outbreaks, especially among susceptible age groups and mainly pregnant women, could be found within the age range of 15 - 44 years. To the best of the authors' knowledge, very few studies have been carried out so far on such a wide age group (six months-95 years), as conducted in this study.

\section{Patients and Methods}

\subsection{Study Population and Sampling}

Five milliliters of blood was collected from each of 1100 participants, of whom 70 were excluded on account of an ongoing infectious disease. Of the 1030 participants whose blood samples were analyzed, 674 were referred to tertiary outpatient clinics for routine medical check-ups, while the rest (356 individuals) were either school students or referrals from health centers. This second group aged six months to 15 years. The study was conducted from November 2011 to May 2012 in Shiraz, southern Iran. The age range of the present population was between six months and 95 years (mean \pm SD: $6.510 \pm 4.502$ ), consisting of 725 females and 305 males. The blood samples were centrifuged at $1000 \mathrm{rpm}$ for 10 minutes at $4^{\circ} \mathrm{C}$ and the plasmas were separated and stored at $20^{\circ} \mathrm{C}$ until the examination time. The design of the study was approved by the Research Ethics Committee at Professor Alborzi Clinical Microbiology Research Center, ref No. 91-10, Shiraz University of Medical Sciences, Shiraz, Iran. Informed consents were obtained from the participants or their legal guardians. Total antibodies and immunoglobulin M (IgM) against HAV and HEV were determined using commercial ELISA kits (Dia. Pro Diagnostic Bioprobes, Milan, Italy). The testing procedure was based on the manufacturer's protocols and sensitivity and specificity of the assays were both $98 \%$. Intermediate test results were checked twice; if in the second round the results were again within the gray zone, the upper limit was considered as positive and lower limit as negative.

\subsection{Statistical Analysis}

The differences between HAV and HEV total antibodies and HAV and HEV IgM among different age groups and genders were analyzed by SPSS software (version 16, SPSS Inc. Chicago, Illinois). P value of less than 0.05 was considered significant.

\section{Results}

Among 1030 individuals, 682 (66.2\%), 6 (0.6\%), 138 (13.4\%) and 9 (0.9\%) were positive for anti-HAV total antibodies, anti-HAV IgM, anti-HEV total antibodies and antiHEV IgM, respectively (Figure 2). The results showed that $113(10.9 \%)$ were positive for both HAV and HEV total antibodies. From all the participants, 356 (34.5\%) were children ( $\leq 15$ years old) and 674 (65.4\%) were adults ( $\geq 16$ years old). In the children group, $65(18.3 \%)$ and $0(0.0 \%)$ were positive for anti-HAV total antibodies and antiHAV IgM, respectively. In addition, 27 (7.6\%) and 2 (0.6\%) were positive for anti-HEV total antibodies and anti-HEV IgM, respectively. In the adults group, 617 (95.3\%) were positive for anti-HAV total antibodies, 6 (0.9\%) for antiHAV IgM, 111 (17.15\%) for anti-HEV total antibodies, and 7 $(1.08 \%)$ for anti-HEV IgM. Positive rates in different age groups in terms of antibodies are presented in Table 1. The difference in the prevalence of positive anti-HAV total antibodies and anti-HEV total antibodies was statistically significant among the age groups $(\mathrm{P}<0.001)$; however, it was not significant for HAV IgM and HEV IgM $(P>0.05$, Figure 1$)$. In addition, the prevalence rates of positive anti-HAV total antibodies, anti-HAV IgM, antiHEV total antibodies and anti-HEV IgM were not significantly different between genders (Table 2).

Table 1. The Prevalence of Hepatitis A Virus and Hepatitis E Virus Antibodies in Different Age Groups a,b

\begin{tabular}{|c|c|c|c|c|c|c|}
\hline & $6-15(n=356)$ & $16-29(n=170)$ & $30-55(n=333)$ & $\geq 56(n=171)$ & Total $(n=1030)$ & P Value \\
\hline HAV Total Antibodies & $65(18.3)$ & $135(79.4)$ & $314(94.3)$ & $168(98.2)$ & $682(66.2)$ & 0.001 \\
\hline HAV IgM & $0(0.00)$ & $1(0.6)$ & $3(0.9)$ & $2(1.2)$ & $6(0.6)$ & 0.297 \\
\hline HEV Total Antibodies & $27(7.6)$ & $25(14.7)$ & $54(16.2)$ & $32(18.7)$ & $138(13.4)$ & 0.001 \\
\hline HEV IgM & $2(0.6)$ & $1(0.6)$ & $2(0.6)$ & $4(2.3)$ & $9(0.9)$ & 0.166 \\
\hline
\end{tabular}

a Abbreviations: HAV: hepatitis A virus; HEV, hepatitis E virus; IgM, immunoglobulin M.

${ }^{b}$ Values are presented as No (\%). 
Asaei Setal.

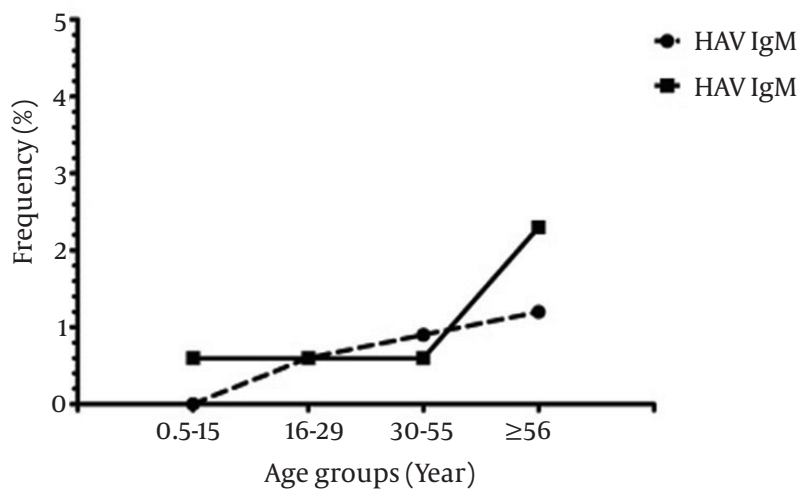

Figure 1. The Prevalence of Hepatitis A Virus and Hepatitis E Virus in Different Age Groups

Table 2. The Prevalence of Hepatitis A Virus and Hepatitis E Virus Antibodies in Different Gender Groups ${ }^{\text {a,b }}$

\begin{tabular}{lccc}
\hline & $\begin{array}{c}\text { Male } \\
(\mathbf{n}=\mathbf{3 0 5})\end{array}$ & $\begin{array}{c}\text { Female } \\
(\mathbf{n}=\mathbf{7 2 5})\end{array}$ & Total \\
\hline HAV Total Antibodies & $121(95.3)$ & $361(95.8)$ & $482(95.6)$ \\
HAV IgM & $1(0.8)$ & $4(1.1)$ & $5(1)$ \\
HEV Total Antibodies & $20(15.7)$ & $66(17.5)$ & $86(17.1)$ \\
HEV IgM & $2(1.6)$ & $4(1.1)$ & $6(1.2)$ \\
\hline
\end{tabular}

a Abbreviations: HAV: hepatitis A virus; HEV, hepatitis E virus; IgM, immunoglobulin $\mathrm{M}$.

$\mathrm{b}$ Values are presented as No (\%).

Figure 2. The Prevalence of Hepatitis A Virus and Hepatitis E Virus Total Antibodies in Different Age Groups

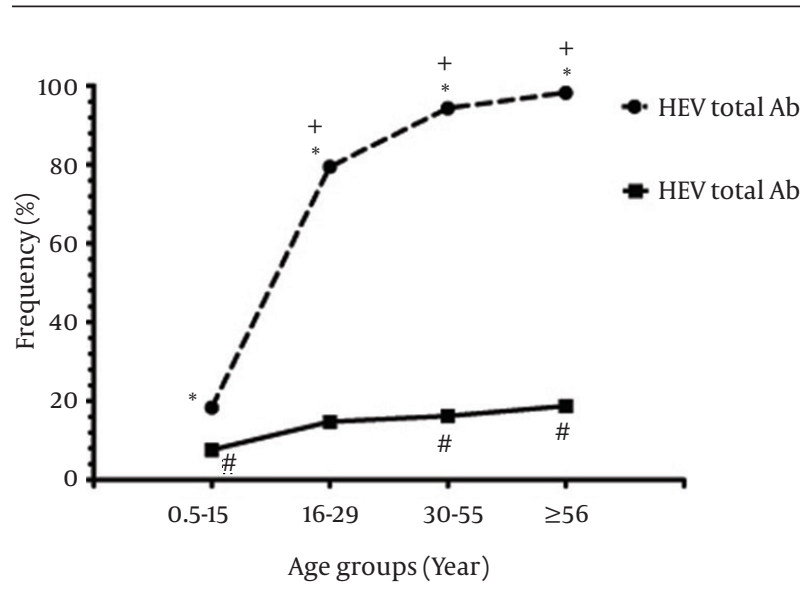

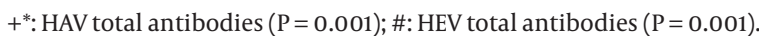

\section{Discussion}

HAV and HEV are among the causative agents of acute hepatitis and global health problems in developed and developing countries $(10,11)$. In endemic regions, over $80 \%$ of the population carry anti-HAV antibodies, where- as the level of anti-HEV antibodies is lower in the same population (12). To the best of knowledge, few studies have been conducted on determining the seroprevalence rates of HAV and HEV infections in southern Iran (13). This study had a unique feature of a wider age range in the studied population. IgM indicates current infections, but there might be IgM-positive individuals who are asymptomatic. These subjects can act as a major source of infection and transmit it to other healthy people, leading to the emergency of HAV and HEV epidemics within the community. In comparison with the present study, other ones have been very limited in terms of number of participants, age groups, and simultaneous detection of both HAV and HEV antibodies.

A previous study in Fars province, southern Iran, indicated that $88.2 \%$ of the general population carried anti-HAV antibodies (13). Another study carried out in three other provinces, i.e. Golestan, (northern Iran), Tehran, (central Iran), and Hormozgan, (southern Iran), showed that the seroprevalence rates of HAV were $99 \%, 85 \%$, and $96 \%$, respectively (14). In the current study, $66.2 \%$ were positive for anti-HAV antibodies and as one of the main routes of transmission for HAV and HEV among general the population is food and water hygiene (15), improving the hygiene program in our region can help eradicate HAV. Few studies performed in Iran on the seroprevalence of HEV demonstrated that its range varies in different regions; 9.3\% in Tehran (16), 3.8\% in Isfahan (17), and 9.6\% and 9.3\% in Nahavand $(18,19)$. The present findings indicated that HEV seropositivity was $13.4 \%$.

Some studies have also demonstrated that HAV and HEV infections have been the most important causes of hepatitis during pregnancy $(20,21)$. HAV infection may lead to preterm delivery (21) and HEV can be associated with increased severity of liver injury in pregnant women (22). The present study revealed that $46.7 \%$ of females were in the reproductive age (15-44 years old), of which $30 \%$ and 17.9\% were positive for anti-HAV and anti-HEV antibodies, respectively. The prevalence of both anti-HAV and HEV IgM was $0.8 \%$ in the same group. As the results showed, there was no anti-HAV IgM-positive female among the six-month to 15 -year-old age group. It may be concluded that the females population infected with HAV are at the reproductive age or older. Taking into account the findings, vaccination against HAV in the abovementioned age range is highly recommended to reduce gestational complications. In addition, controlling measures against HEV infection should be considered in this population.

According to the results, the prevalence of anti-HAV (IgG and IgM) and anti-HEV (IgG and IgM) increased with age. To reduce the incidence of HAV and HEV infections, HAV vaccination campaign across the nation, intensive controlling measures and surveillance for HEV, and hygienic improvement in food preparation and water sources are suggested. In addition, to reduce the risk of transmission to children, adults with acute HAV and HEV infections who work in child care centers and food outlets must 
not work at least one week after the onset of illness (23). Clinical manifestations of HAV infections vary and may be entirely asymptomatic, especially in children. In such conditions, HAV can be detected only by viral serological assays or abnormal liver tests (24). Similarly, HEV-infected individuals may not present any clinical signs (25). In the present study, all the patients with IgM against HAV or HEV were asymptomatic.

The results also showed that HAV IgG and IgM were not seen at the childhood age (six months to 15 years old); so, this group is more susceptible to the infections. Furthermore, HAV and HEV infections were positively correlated with age. Therefore, HAV vaccination and controlling the measures for HEV are recommended. Considering the importance of infections in the gestational period, such programs should focus more on girls. Since both HAV and HEV infections are currently epidemic in developing nations, health authorities should pay more attention and take measures against these diseases, which may help reduce and better control the future outbreaks in Iran.

\section{Acknowledgements}

Our thanks should go to Dr. Hassan Khajehei for copy editing the manuscript. We also thank Motahari Clinic for its help with finding the patients.

\section{Authors' Contributions}

Mazyar Ziyaeyan developed the original idea and the protocol. Sadaf Asaei wrote the manuscript, and was the guarantor, analyzed the data, contributed to the development of the protocol, abstracted the data, and prepared the manuscript. Mahsa Moeini contributed to the development of the protocol. Marzieh Jamalidoust developed and prepared the manuscript. Mohammad Amin Behzadi designed the curve.

\section{Funding/Support}

This study was financially supported by Grant No. 90-10 awarded by Prof. Alborzi Clinical Microbiology Research Center, Shiraz University of Medical Sciences, Shiraz, Iran.

\section{References}

1. Costa-Mattioli M, Di Napoli A, Ferre V, Billaudel S, Perez-Bercoff R, Cristina J. Genetic variability of hepatitis A virus. J Gen Virol. 2003;84(Pt 12):3191-201.

2. Yong HT, Son R. Hepatitis A virus. Int Food Res J. 2009;16:455-67.

3. Vilibic-Cavlek T, Kucinar J, Ljubin-Sternak S, Kolaric B. Seroepidemiology of hepatitis a in the croatian population. Hepat Mon. 2011;11(12):997-9.
4. Vancelik S, Guraksin A, Alp H. Hepatitis A seroepidemiology in Eastern Turkey. East Afr Med J. 2006;83(2):86-90.

5. Lee H, Cho HK, Kim JH, Kim KH. Seroepidemiology of hepatitis A in Korea: changes over the past 30 years. J Korean Med Sci. 2011;26(6):791-6.

6. Tei S, Kitajima N, Takahashi K, Mishiro S. Zoonotic transmis sion of hepatitis E virus from deer to human beings. Lancet 2003;362(9381):371-3.

7. Chandra V, Taneja S, Kalia M, Jameel S. Molecular biology and pathogenesis of hepatitis E virus. J Biosci. 2008;33(4):451-64.

8. Ghorbani GA, Alavian SM, Esfahani AA, Assari S. Seroepidemiology of Hepatitis E Virus in Iranian Soldiers. Hepat mon. 2007;7(3):123-6.

9. Sepanlou S, Rezvan H, Amini-Kafiabad S, Dayhim M, Merat S. A Population-based Seroepidemiological Study on Hepatitis E Virus in Iran. Middle East J Dig Dis. 2010;2(2):97-103.

10. Livni G, Plotkin S, Yuhas Y, Chodik G, Aloni H, Lerman Y, et al. Seroepidemiology of hepatitis A antibodies among children's hospital staff. Pediatr Infect Dis J. 2002;21(7):618-22.

11. Reyes GR, Purdy MA, Kim JP, Luk KC, Young LM, Fry KE, et al. Isolation of a cDNA from the virus responsible for enterically transmitted non-A, non-B hepatitis. Science. 1990;247(4948):1335-9.

12. Ungan M, Yaman H, Taheri N. The seroprevalence of specific antibodies to hepatitis A virus in a Turkish population. Eur J Gastroenterol Hepatol. 2002;14(9):1033-4.

13. Taghavi SA, Hosseini Asl MK, Talebzadeh M, Eshraghian A. Seroprevalence study of hepatitis A virus in Fars province, southern Iran. Hepat Mon. 2011;11(4):285-8.

14. Merat S, Rezvan H, Nouraie M, Abolghasemi H, Jamali R, AminiKafiabad S, et al. Seroprevalence and risk factors of hepatitis A virus infection in Iran: a population based study. Arch Iran Med. 2010;13(2):99-104.

15. Traore KA, Rouamba H, Nebie Y, Sanou M, Traore AS, Barro N, et al Seroprevalence of fecal-oral transmitted hepatitis A and E virus antibodies in Burkina Faso. PLoS One. 2012;7(10):e48125.

16. Mohebbi SR, Rostami Nejad M, Tahaei SM, Pourhoseingholi MA, Habibi M, Azimzadeh P, et al. Seroepidemiology of hepatitis A and $\mathrm{E}$ virus infections in Tehran, Iran: a population based study. Trans R Soc Trop Med Hyg. 2012;106(9):528-31.

17. Ataei B, Nokhodian Z, Javadi AA, Kassaian N, Shoaei P, Farajzadegan Z, et al. Hepatitis E virus in Isfahan Province: a populationbased study. Int J Infect Dis. 2009;13(1):67-71.

18. Taremi M, Mohammad Alizadeh AH, Ardalan A, Ansari S, Zali MR. Seroprevalence of hepatitis E in Nahavand, Islamic Republic of Iran: a population-based study. East Mediterr Health J. 2008;14(1):157-62.

19. Zali MR, Taremi M, Arantibodiesi S, Ardalan A, Alizadeh AHM, An sari S. Seroprevalence of hepatitis E in Nahavand, Iran: Apopulation-based study. East Mediterr Health J. 2008;14(1):157-62.

20. Hoofnagle JH, Nelson KE, Purcell RH. Hepatitis E. N Engl J Med. 2012;367(13):1237-44

21. Elinav E, Ben-Dov IZ, Shapira Y, Daudi N, Adler R, Shouval D, et al Acute hepatitis A infection in pregnancy is associated with high rates of gestational complications and preterm labor. Gastroenterology. 2006;130(4):1129-34.

22. Navaneethan U,Al Mohajer M, Shata MT. Hepatitis E and pregnancy: understanding the pathogenesis. Liver Int. 2008;28(9):1190-9.

23. Larry K, Carol JB, David WK, Sarah SL. Red Book. 28 edAmerica: American Academy of pediatrics; 2009.

24. Tong MJ, el-Farra NS, Grew MI. Clinical manifestations of hepatitis A: recent experience in a community teaching hospital. JInfect Dis.1995;171 Suppl 1:S15-8.

25. Panda SK, Thakral D, Rehman S. Hepatitis E virus. Rev Med Virol. 2007;17(3):151-80. 